\title{
Desain Multimedia Pembelajaran Tari Rakyat Berbasis Android Sebagai Self Directed Learning Mahasiswa Dalam Perkuliahan
}

\author{
Heni Komalasari, Agus Budiman¹, Juju Masunah, Ayo Sunaryo \\ Departemen Pendidikan Seni Tari, Fakultas Pendidikan Seni Dan Desain \\ Universitas Pendidikan Indonesia \\ Jln. Dr. Setiabudhi No. 229 Bandung \\ 'agusbudiman@upi.edu,
}

Pendekatan sumber belajar konvensional saat ini lambat laun mulai beralih atau bertransformasi menuju pendekatan sumber belajar digitalisasi. Tujuan penelitian ini ingin mengembangkan protipe pembelajaran tari rakyat berbasis android yang dapat dimanfaatkan oleh mahasiswa sebagai pendekatan pembelajaran self directed learning pada perkuliahan tari rakyat. Metode penelitian yang digunakan dalam penelitian ini adalah metode penelitian pengembangan. Data penelitian diperoleh dari hasil studi dokumentasi dan studi literatur. Analisis data disajikan secara kualitatif untuk mendeskripsikan secara detail mengenai langkah-langkah proses penyusunan prototipe multimedia pembelajaran tari rakyat berbasis android. Temuan menunjukan bahwa protipe sumber belajar multimedia tari rakyat berbasis android yang dikembangkan memiliki karakteristik dalam mendorong mahasiswa untuk dapat melakukan belajar secara mandiri tanpa harus dibimbing dan dilatih langsung oleh dosen di dalam jam perkuliahan. Model media yang dikembangkan menyajikan beberapa menu pilihan belajar yang dapat diakses oleh mahasiswa melalui berbagai perangkat teknologi seperti komputer, laptop, seluler, dan lain sejenisnya.

Kata Kunci : Multimedia, Pembelajaran Tari, Self Directed Lerning, Teknologi Pembelajaran,

\section{Android-Based Multimedia Design for Learning Folk Dance as Self-Directed Learning for Students in Lectures}

The conventional learning resource approach is currently starting to shift or transform towards a digitalized learning resource approach. The purpose of this study is to develop an android-based folk dance learning prototype that can be used by students as a self-directed learning approach in folk dance lectures. The research method used in this research is development research method. The research data were obtained from the results of documentation studies and literature studies. Data analysis is presented qualitatively to describe in detail the steps of the process of preparing a multimedia prototype for learning Android-based folk dance. The findings show that the developed prototype of multimedia folk dance learning resources developed has characteristics in encouraging students to be able to learn independently without having to be guided and trained directly by the lecturer during lecture hours. The media model developed presents several menu of learning options that can be accessed by students through various technological devices such as computers, laptops, cellphones, and others.

Keywords: Multimedia, Dance Learning, Self Directed Lerning, Learning Technology,

Proses Review : 2 - 28 Januari 2021, Dinyatakan Lolos: 18 Februari 2021 


\section{PENDAH ULUAN}

Teknologi dalam pendidikan keberadaannya sudah tidak dapat dipisahkan lagi. Keberadaannya mampu menghubungkan berbagai pengetahuan dan informasi global yang dapat diakses dalam pembelajaran (Fletcher, Everatt, Mackey, \& Fickel, 2020). Pemanfaatan teknologi dalam pendidikan mampu mengubah mindset penyelenggaraan pendidikan di sekolah yang awalnya teacher center menjadi student center. Kehadiran teknologi berkontirbusi positif dalam dunia pendidikan (Bond, Marín, Dolch, Bedenlier, \& Zawacki-Richter, 2018; Castañeda \& Selwyn, 2018; Watermeyer, Crick, Knight, \& Goodall, 2020). Pembelajaran dengan menggunakan teknologi akan meningkatkan keterlibatan siswa untuk belajar secara mandiri, meningkatkan minat dan motivasi belajar sehingga mampu mewujudkan pembelajaran yang lebih aktif, kreatif, inovatif(Sliwka, 2008), dan mandiri karena berpusat pada aktivitas belajar siswa.

Dewasa ini sudah banyak dan sering didengar mahasiswa belajar dibantu dengan teknologi baru. Kondisi ini menandakan bahwa perkembangan zaman telah melahirkan manusia-manusia dengan kebutuhan baru. Begitu juga dengan pengembangan sumber belajar yang saat ini lebih kepada perangkat lunak (software) dengan alasan dapat digunakan atau dimanfaatkan tanpa mengenal waktu dan tempat. Generasi muda yang lebih menyukai media teknologi dalam aktivitas sehari-harinya bukan sesuatu yang dapat dihidari lagi (Brata \& Sudirga, 2019). Saat ini generasi mudah banyak beraktivitas melalui perangkat android (Widiastuti, 2018). Generasi muda Generasi saat ini dikenal sebagai "digital natives", yaitu generasi yang tumbuh dan dibesarkan di tengah dunia teknologi digital. Maka sangat relevan jika pengembangan sumber belajar digital diperuntukan bagi mahasiswa sebagai pendekatan self directed learning. Keberadaan media dalam pembelajaran mampu merangsang daya berpikir siswa agar dapat memahami materi pelajaran yang diberikan guru dengan cara memperhatikan media yang digunakan dalam pembelajaran. (Kozma, 1991; Mayer, 2002; Roblyer \& Doering, 2006).

Media pembelajaran merupakan salah satu komponen perangkat pembelajaran yang penting untuk dipersiapkan secara baik (Falahudin, 2014). Pemanfaatan media dalam pembelajaran agar mampu mewujudkan pembelajaran yang efektif dan efisien. (Rusdewanti \& Gafur, 2014). Salah satu cara belajar efektif dengan menggunakan media adalah dengan memanfaatkan multimedia seperti video. (DeWitt et al., 2013). Media yang digunakan dalam mewujudkan pembelajaran efektif seyogiayanya di desain secara kreatf sehingga dapat membantu memperlacar dan meningkatkan efisiensi dalam pencapaian tujuan dari pembelajaran. (Kurniawati \& Nita, 2018). Selain itu, penggunaan media pembelajaran yang menarik akan mampu menumbuhkan motivasi bagi siswa dan menjadikan pembelajaran menjadi lebih menarik bagi siswa. (Sma \& Pati, 2012). Penggunaan multimedia dalam pembelajaran dapat menunjukan adanya perubahan cara belajar dari pendekatan cara belajar konvensional menuju pendekatan cara belajar yang lebih modern dan adaptif dengan perkembangan zaman saat ini.(Jauhari, 2009).

Beberapa penelitian tentang media pembelajaran seni tari berbasis multimedia interaktif telah diteliti sebelumnya. (Putri, Rahmawati, \& Wiharsih, 2019) meneliti tentang uji kelayakan produk pengembangan media pembelajaran tari berbasis multimedia interaktif untuk sasaran siswa sekolah menengah pertama. (Almara'beh, Amer, \& Sulieman, 2015) meneliti tentang pengembangan desain multimedia untuk kebutuhan pendidikan. (Budiman \& Amadi, 2016) meneliti tentang pengembangan aplikasi pembelajaran Seni Tari Dhungkrek dengan menggunakan IGN SDK Framework yang terdapat pada platform open source. (Tongpaeng, Sribunthankul, \& Sureephong, 2018) meneliti tentang pengembangan multimedia pembelajaran tari yang digunakan untuk membandingkan antara gerakan ahli tari Thailand yang direkam dengan Motion Capture Sistem dan gerakan Real-Time Dance dengan sensor gerak Microsoft Kinect untuk memeriksa keakuratan dan mengevaluasi gerakan tariannya. Namun, belum ada hasil penelitian yang mengembangkan media pembelajaran tari berbasis multimedia interaktif yang bersinergi dengan silabus perkuliahan sesuai dengan kebutuhan pertemuan dalam perkuliahan praktek tari. Dalam materi media yang dikembangkan terdapat pilihan menu pengetahuan tentang latar belakang tarian, busana, gerak, tata rias, video panduan pembelajaran tari dalam beberapa part pertemuan, video tarian yang ditayangkan secara utuh dan kuis pertanyaan untuk mengukur pemahaman mahasiswa terhadap materi yang diberikan.

Undang-undang No. 20 Tahun 2003 tentang Sistem Pendidikan Nasional menyatakan bahwa pendidikan adalah usaha sadar dan terencana untuk mewujudkan suasana belajar dan proses pembelajaran agar peserta didik secara aktif mengembangkan potensi dirinya untuk memiliki kekuatan spiritual keagamaan, pengendalian diri, kepribadiasn, akhlak mulia, serta keterampilan dirinya, masyarakat, bangsa, dan negara (Indonesia, 2003). Isi undang-undang tersebut menunjukan bahwa proses pendidikan itu harus berorientasi kepada siswa (student centered). Dengan demikian pendidikan adalah upaya mengembangkan potensi anak didik (Slameto, 2003).

Agar terealisasi tujuan pendidikan tersebut maka perlu adanya pembelajaran yang inovatif. Mengajar merupakan kegiatan yang kompleks, yaitu penggunaan secara integratif sejumlah keterampilan untuk menyampaikan pesan kepada mahasiswa. Kegiatan pembelajaran yang diterapkan di dalam kelas maupun luar kelas, diutamakan memiliki strategi pembelajaran yang beranekaragam, bergitu juga dengan ketersediaan sumber belajar yang ada. 
Karakteristik mahasiswa yang termasuk pada kategori usia dewasa awal menunjukan kemandirian belajarnya, hal ini menunjukan terbentuknya kedewasaan diri. Cara belajar mahasiswa lebih cenderung dilakukan secara mandiri dalam menganalisis dan memecahkan berbagai masalahnya (Rahman, 2019).

Seiring dengan berkembangnya ilmu pengetahuan dan teknologi, definisi mengajar juga mengalami perubahan yaitu bimbingan kepada siswa dalam proses belajar" (Slameto, 2003). Perubahan cara belajar dan mengajar ini terkait pula dengan adanya perubahan sosial di masyarakat (Jarvis, 2004, 2007; Merriam \& Baumgartner, 2020; Merriam \& Brockett, 2011). Pendapat tersebut menunjukan bahwa yang aktif adalah mahasiswa yang mengalami proses belajar, sedangkan dosen hanya membimbing, menunjukan jalan dengan mempertimbangkan kepribadian dan karakteristik mahasiswa. Penting kiranya dosen memahami gaya belajar mahasiswa yang memliki kecenderungan mandiri dalam memecahkan berbagai persoalan pembelajaran dengan pengalaman dan kecerdasan yang dimiliki masing-masing mahasiswa (Papilaya \& Huliselan, 2016; Ru'iya, 2019; Triman \& Abdillah, 2017).

Sumber belajar yang disusun by design oleh Dosen kepada mahasiswa, memiliki tujuan sebagai penguatan materi dan ditujukan untuk kepentingan belajar mandiri. Melalui pemanfaatan sumber belajar by disgn, mahasiswa akan dibawa kepada iklim "kebebasan dalam belajar" mengdlola dirinya sendiri dalam kegiatan belajar. Seperti pendapat (Rusman \& Riyana, 2011) bahwa pembelajaran akan bermakna apabila pembelajar mempunyai kesempatan untuk ikut menentukan tujuan pembelajaran yang ingin dicapai sesuai dengan kondisi dan kebutuhan belajarnya, ikut menentukan bahan belajar yang ingin dipelajarinya dan cara mempelajarinya, mempunyai kebebasan untuk belajar sesuai kecepatan sendiri, dan ikut menentukan cara evaluasi yang akan digunakan untuk menilai kemajuan belajarnya. Konsep ini yang dikenal pula sebagai model self directed learning, dimana mahasiswa diberikan otonomi dalam mengelola belajarnya yang mengarah kepada kemandirian belajar.

(Knowles, 1975) menjelaskan pula bahwa self directed learning adalah sebuah proses di mana individu mengambil inisiatif, dengan atau tanpa bantuan orang lain, dan proses dalam self-directed learning ini dilakukan dengan menyadari kebutuhan sendiri dalam belajar, mengatur tujuan pribadi, membuat keputusan pada sumber dan strategi belajar dan menilai hasil. Dalam selfdirected learning seseorang memiliki kebebasan dalam merencanakan dan menentukan sendiri tujuan pembelajaran yang dilakukan (Beishuizen \& Steffens, 2011; Gibbons, 2003; Lee, Tsai, Chai, \& Koh, 2014). Belajar adalah tanggung jawab mahasiswa sendiri, sehingga proses pembelajaran yang dilakukan juga optimal. Dalam hal ini self-directed learning mengembangkan secara optimal kemandirian belajar yang dimiliki mahasiswa selama proses pembelajaran. Mahasiswa merupakan individu belajar yang sudah memiliki pengalaman sebelumnya untuk dijadikan sebagai referensi kesadaran dalam melakukan pembelajaran selanjutnya (Istiyani, 2009).

Penelitian ini memiliki tujuan dalam mengembangkan multimedia pembelajaran tari rakyat berbasis android untuk dijadikan sebagai pendekatan self direrected learning mahasiswa dalam perkuliahan praktek tari rakyat di Departemen Pendidikan Seni Tari FPSD UPI. Karakteristik model media yang dikembangkan berdasarkan hasil analisis kondisi pembelajaran praktek tari rakyat yang teramati berdasarkan input, proses dan output mata kuliah yang kecenderungannya mengarah pada proses kegiatan belajar berpraktik yang menuntut dosen dan mahasiswa untuk lebih banyak bergerak secara langsung daripada mengkondisikan pola pembelajaran secara klasikal dan teoritis. Protipe multimedia pembelajaran tari rakyat berbasis android ini akan menjadi salah satu model media pembelajaran tari berbasis multimedia yang dapat diakses oleh mahasiswa melalui aplikasi mobile-handphone. Aplikasi media pembelajaran tari rakyat ini direkomendasikan sebagai alternative sumber media pembelajaran yang dapat dilakukan secara mandiri oleh dosen dan mahasiswa dalam sebuah pendekatan pembelajaran blanded learning.

\section{METODE}

Penelitian pengembangan ini dilakukan berdasarkan acuan hasil modifikasi model-model penelitian diantaranya : model penelitian Borg \& Gall (2003:775), model pengembangan desain pembelajaran (Dick, Carey, \& Carey, 2005). Tahapan-tahapan penelitian dilakukan dengan memperhatikan secara detail proses tahapan penelitian dengan karakteristik desain penelitian pengembangan. Adapun secara prosedur tahapan penelitian ini dilakukan, sebagai berikut:

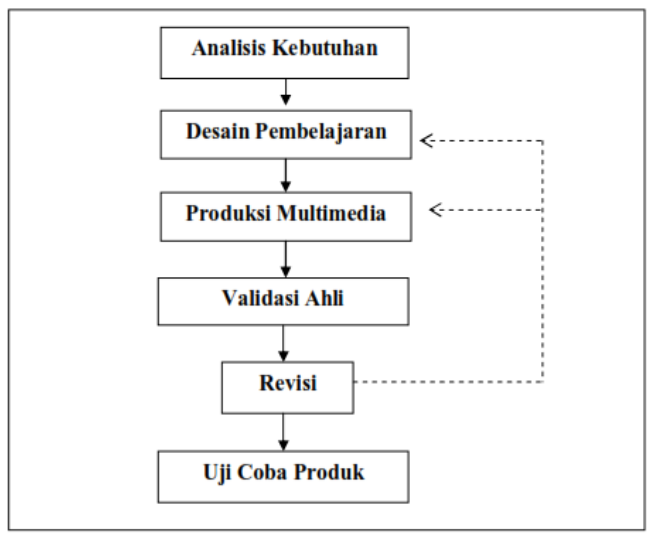

Gambar 1. Adaptasi konsep model Borg \& Gall (2003). Dick and Carey (2005) 
Berdasarkan gambar 3 menunjukan bahwa penelitian ini melalui 6 tahap, diantaranya :

1. Tahap analisis kebutuhan, tahap ini bertujuan untuk mengumpulkan informasi terkait dengan permasalahan mahasiswa dalam mempelajari materi tari rakyat melalui media pembelajaran yang sudah ada.

2. Tahap desain pembelajaran, tahap ini merupakan tahap penyesuain silabus mata kuliah dengan media pembelajaran yang dikembangkan.

3. Tahap produksi/ pengembangan multimedia, tahap ini akan menghasilkan produk awal, produk yang secara operasional sudah dapat digunakan namun masih memerlukan masukan-masukan untuk mengukur efektifitas dan relevansi produk.

4. Tahap validasi ahli, tahap ini bertujuan untuk mengetahui kekurangan-kekurangan atau masukan dari pakar media pembelajaran.

5. Tahap revisi, melalui tahap ini media yang telah diberikan masukan oleh pakar di revisi dan disesuaikan dengan saran dan kritik pakar.

6. Tahap ujicoba produk, tahap ini dilakukan untuk mengetahui daya tarik multimedia yang dikembangkan untuk mahasiswa dengan melihat pre-test dan posttest sebagai hasil ketuntasan belajarnya melaui self directed learning.

\section{HASIL PENELITIAN}

Kemandirian belajar yang dilakukan oleh mahasiswa dalam pembelajarannya dapat ditunjang dengan sumber belajar yang terkondisikan oleh dosen atau disebut sebagai sumber belajar by design. Sumber belajar by desgin disusun berdasarkan kepada kebutuhan dan tujuan belajar itu sendiri, melaui prosedur yang terstruktur mulai dari penyusunan skenario, strory board, uji validasi sumber belajar oleh pakar, penyusunan protipe, uji coba kepada mahasiswa, hingga menjadi produk akhir.

Dalam mengembangakan Multimedia Interaktif terdapat 6 tahapan yaitu tahap konsep (concept), perencanaan (design), pengumpulan bahan (material collecting), pembuatan (assmbly), uji coba (testing) dan distribusi (distribution).

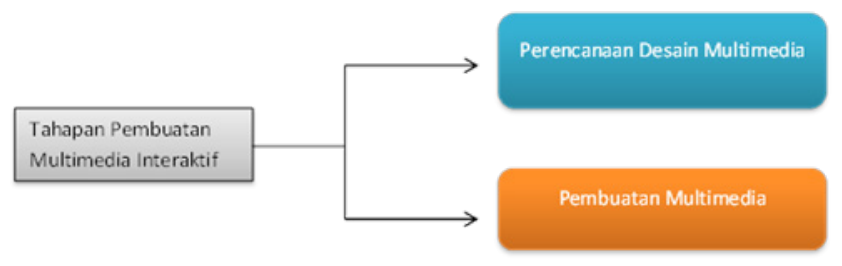

Gambar 2. Tahapan Pembuatan Multimedia Interaktif

Tahapan dalam analisis pembuatan multimedia interaktif tari rakyat meliputi pemilihan materi, penentuan pemakai (user) dan indikator kebutuhan belajar mahasiswa pada mata kuliah tari rakyat. Ke tiga proses ini dilakukan secara bersamaan karena saling berkaitan dan tidak bisa berdiri sendiri. Materi yang dipilih dalam penelitian ini adalah pembelajaran tari rakyat yang berhubungan dengan materi tari polostomo yang diberikan dalam mata kuliah tari rakyat. Desain rancangan layout desain yang baik dan terencana akan mempermudah pembuatan aplikasi selanjutnya. Sebelum membuat media pada software yang digunakan, penulis merancang desain pada storyboard (skenario/alur cerita) dan mempersiapkan prototype (rancangan awal) dari media yang akan dibuat. Perencanaan program harus dipersiapkan secara matang untuk memperlancar proses selanjutnya. Perencanaan pengembangan multimedia pembelajaran tari rakyat ini disesuaikan dengan kebutuhan dan karakteristik dalam perkuliahan tari rakyat yang diberikan di Departemen Pendidikan Seni Tari FPSD UPI. Dalam kegiatan penelitian digunakan beberapa langkah mudah dalam mengembangkan mengembangkan multimedia pembelajaran tari rakyat berbasis android, sebagai berikut.

\section{Menentukan Jenis Multimedia Interaktif Pembelajaran Berbasis Android}

Perhatikan dengan benar, yang akan kita buat itu apakah alat bantu kita untuk mengajar (presentasi) ke mahasiswa atau kita arahkan untuk bisa dibawa pulang mahasiswa alias untuk belajar mandiri di rumah/tempat kost atau di kampus. Jenis multimedia pembelajaran menurut kegunannya ada dua:

1. Multimedia Presentasi Pembelajaran: Alat bantu dosen dalam proses pembelajaran di kelas dan tidak menggantikan dosen secara keseluruhan. Berupa pointer-pointer materi yang disajikan (explicit knowledge) dan bisa saja ditambahi dengan multimedia linear berupa film dan video untuk memperkuat pemahaman mahasiswa. Dapat dikembangkan dengan software presentasi seperti: Open Office Impress, Microsoft Power Point, dsb.

2. Multimedia Pembelajaran Mandiri: Software pembelajaran yang dapat Dimanfaatkan oleh siswa secara mandiri alias tanpa bantuan dosen. Multimedia pembelajaran mandiri harus dapat memadukan explicit knowledge (pengetahuan tertulis yang ada di buku, artikel, dsb) dan tacit knowledge (know how, rule of thumb, pengalaman dosen). Tentu karena menggantikan dosen, harus ada fitur assesment untuk latihan, ujian dan simulasi termasuk tahapan pemecahan masalahnya. Untuk level yang kompleks dapat menggunakan software semacam Macro media Author ware atau Adobe Flash.

\section{Menentukan Tema Materi Ajar}

Ambil tema bahan ajar yang menurut kita sangat membantu meningkatkan pemahaman ke mahasiswa dan menarik bila kita gunakan multimedia interaktif. Ingat bahwa tujuan utama kita membuat multimedia pembelajaran adalah untuk meningkatkan pemahaman 
mahasiswa sehingga ada inisiatif untuk melaksanakan pembelajaran mandiri baik di dalam kampus maupun di luar kampus. Materi yang dikembangkan dalam media pembelajaran ini adalah materi tari rakyat (tari polostomo). Materi tari polostomo merupakan salah satu materi tari rakyat yang diberikan kepada mahasiswa selain materi tari sulanjana dan tari blantek yang diberikan pada mata kuliah tersebut. Materi tari polostomo ini dikemas sesuai dengan kebutuhan perkuliahan tari rakyat yang diberikan selama 16 kali pertemuan dalam satu semester. Dalam langkah kesempatan ini, materi tari polostomo akan didesain menjadi satu bahan ajar bagi mahasiswa berbasis teknologi yang memiliki tingkat efektifitas pembelajaran yang mampu dimanfaatkan oleh mahasiswa untuk dijadikan sumber belajar baik di dalam kampus maupun di luar kampus.

\section{Materi Tari Rakyat}

Mata kuliah tari rakyat adalah salah satu mata kuliah yang memiliki tujuan kompetensi dalam memberikan pengetahuan dan keterampilan terhadap mahasiswa dalam menguasai materi tari rakyat berdasarkan penguasaan aspek wiraga, wirahma dan wirasa. Bobot sks mata kuliah ini adalah 4 sks yang mesti ditempuh oleh dosen dan mahasiswa selama 32 kali pertemuan. Dalam 32 kali pertemuan ini mahasiswa diberikan 3 materi tari yakni tari polostomo, tari blantek dan tari sulanjana. Kegiatan perkuliahan yang dilakukan dalam setiap pertemuannya lebih banyak dilakukan secara praktik dengan pendekatan metode konvensional. Persoalan yang sering dijumpai ketika praktik adalah Dosen harus mengulangi kembali gerakan-gerakan yang dianggap lupa oleh mahasiswa, bahkan harus mengulanginya lagi dari awal, sehingga akan banyak memakan waktu dan output pembelajaran tidak tercapai optimal. Kondisi ini tidaklah efektif baik untuk dosen sebagai pengajar maupun mahasiswa sebagai subjek belajar, karena kecenderungan yang terjadi kurang mampu mendewasakan mahasiswa sebagai subjek belajar yang seharusnya mamapu mengembangkan potensinya sendiri secara mandiri melalui intruksional yang diberikan dosen dalam penugasannya. Hanya saja, kenyataan saat ini bahwa mayoritas dosen dalam memberikan materi mata kuliah praktik kurang mampu mengembangkan sumbersumber belajar yang mampu menciptakan kemandiri optimal terhadapat mahasiswa itu sendiri. Keberadaan seni pertunjukan tradisional rakyat yang berkembang di Jawa Barat memiliki keragaman bentuk dan jenis pertunjukan yang disesuaikan dengan fungsi pertunjukannya di masyarakat. Setiap seni pertunjukan tradisional yang diciptakan suatu masyarakat tertentu dan berkembang di berbagai daerah di Jawa Barat memiliki tujuan tertentu untuk memenuhi segala harapan dan keinginan masyarakat penyangganya untuk menjaga keberlangsungan pola hidupnya. Seiring dengan proses yang panjang, jenisjenis seni pertunjukan tradisional yang berkembang di masyarakat Jawa Barat mampu memberikan identitas semangat jamannya. Beberapa ahli seni menyebutkan ada 3 bagian klasifikasi masa keemasan atau perioderisasi perkembangan seni yakni perkembangan seni pada jaman primitif, feodal dan modern. Dari ketiga masa keemasan ini banyak melahirkan bentuk-bentuk seni pertunjukan tradisional rakyat yang selalu memiliki keunikan khas dari penyajiannya.

Pada umumnya karya atau produk seni pertunjukan tradisional di masyarakat tidak diketahui identitas penciptanya atau dikenal dengan istilah Anonim. Karya seni pertunjukan tradisional yang lahir diciptakan seniman tidak semata demi kepentingan mencari uang atau popularitas pribadi, seperti yang pada umumnya terjadi dewasa ini. Tetapi, banyak karya seni yang dilahirkan demi keberlangsungan kehidupan masyarakat banyak. Salah satu contoh konkritnya adalah pada seni pertunjukan sebagai ritual, yang hampir dari setiap pelosok daerah di Jawa Barat memiliki seni pertunjukan tradisional rakyat sebagai fungsi ritual. Tidak hanya pada kepentingan ritual dan upacara, masih banyak lagi jenis-jenis seni pertunjukan tradisional rakyat yang memiliki fungsi lain, seperti fungsi hiburan yang diciptkan seniman dulu dan masih berkembang saat ini tanpa diketahui siapa penciptanya. Seperti dalam seni pertunjukan ketuk tilu, kesenian bangreng, bajidor, dll. Jenis-jenis kesenian ini tumbuh dengan sendirinya, tanpa diketahui secara pasti siapa seniman pertama yang menciptakannya.

Pengembangan multimedia agar dapat dimasukkan dalam pembelajaran harus melalui tahapan-tahapan yang terancang dengan baik dan runtut agar produk multimedia yang dihasilkan memiliki kualitas yang baik dan tepat digunakan dalam pembelajaran. Pengembangan multimedia dapat dilakukan dengan metode Multimedia Development Life Cycle (MDLC) yang terdiri dari 6 tahap. Tahapan dalam pembuatan media pembelajaran tari rakyat berbasis multimedia ini dimulai dari tahap konsep sampai dengan tahap distribusi. Berikut adalah penjelasan dari masing-masing tahapan tersebut.

\section{a. Konsep (Concept)}

Tahap awal dalam pembuatan media pembelajaran tari rakyat berbasis multimedia ini adalah menentukan konsep. Adapun konsep dasar dari pengembangan media pembelajaran tari rakyat berbasis multimedia ini adalah untuk membantu dosen dan mahasiswa dalam melakukan interaksi pembelajaran yang tidak harus dilakukan dalam pendekatan konvensional klasikal melalui kegiatan tatap muka langsung, tetapi dengan adanya media ini dapat memberikan ruang belajar yang tidak terbatas dengan ruang dan waktu sekaligus meningkatkan kesadaran mahasiswa untuk melakukan pembelajaran secara mandiri (self directed learning). Materi media yang dikembangan mengacu pada kebutuhan materi pembelajaran yang akan dilakukan pada perkuliahan tari rakyat dengan berpedoman pada silabus mata kuliah. 


\section{b. Perancangan (Desain)}

Terdapat beberapa pilihan menu yang terdapat pada desain multimedia yang dikembangkan untuk memenuhi kebutuhan belajaran mahasiswa. Dalam konsep multimedia pembeajaran tari rakyat ini didesain dalam bentuk aplikasi pembelajaran berbasis android. Aplikasi media pembelajaran ini agar dapat diakses oleh mahasiswa kapan dan dimana saja. Berikut adalah desain storyboard dari media pembelajaran tari Rakyat yang akan dikembangkan:

1. Tampilan Awal Aplikasi

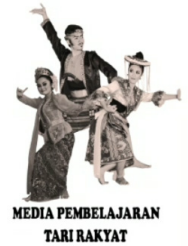

Gambar 3. Tampilan Awal Aplikasi

\section{Login Aplikasi}

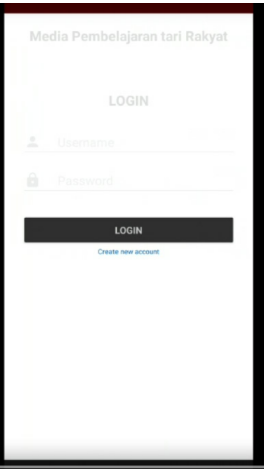

\section{Storyboard Menu Utama}

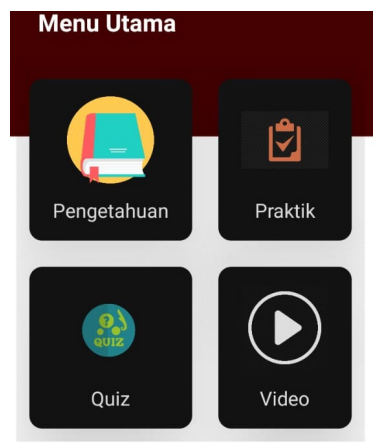

Gambar 3. Menu utama multimedia

\section{Storyboard Menu Pengetahuan}
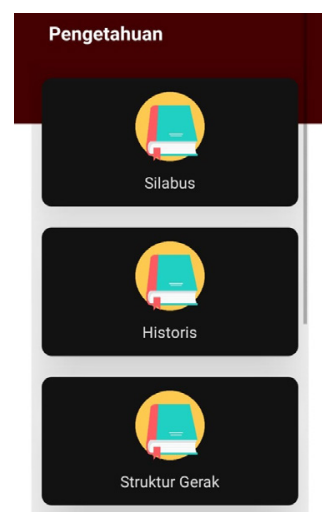

Gambar 4. Menu pengetahuan multimedia 5. Storyboard Menu Praktik

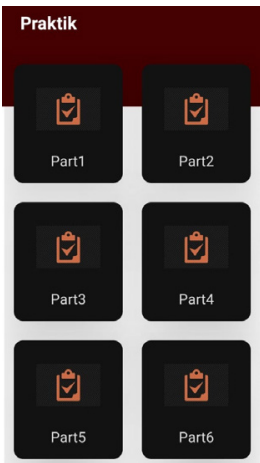

Gambar 5. Menu Praktik

6. Storyboard Menu Quis

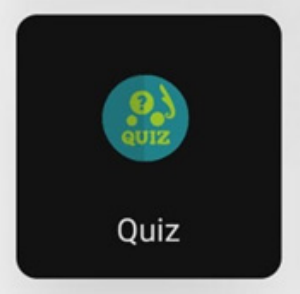

Gambar 5. Menu Quis

\section{Storyboard Menu Video}

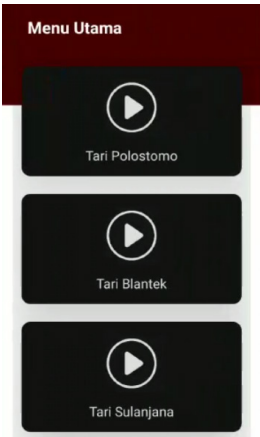

Gambar 5. Menu Video 


\section{c. Pengumpulan Bahan (Material Collecting)}

Bahan yang dibutuhkan untuk pengembangan media pembelajaran tari rakyat ini yaitu deskripsi materi tarian (sejarah singkat tarian, nama-nama gerak, silabus perkuliahan, gambar rias dan busana, deskripsi singkat tentang musik iringan tari, soal dan jawaban quis) video tarian utuh.

\section{d. Pembuatan (Assembly)}

Tahap ini berupa tampilan media pembelajaran dari desain yang akan diaktualisasikan kepada pengguna. Menu yang ada dalam aplikasi ini dirancang sedemikian rupa dengan rancangan yang menarik,interaktif dan user friendly.

\section{e. Testing (Pengujian)}

Tahap testing (pengujian) dilakukan setelah menyelesaikan tahap pembuatan (assembly) dengan menjalankan aplikasi/ program dan dilihat apakah ada kesalahan atau tidak. Tahap pertama pada tahap ini disebut juga sebagai tahap pengujian alpha (alpha test) yang pengujiannya dilakukan oleh pembuat atau lingkungan pembuatnya sendiri. Setelah lolos dari pengujian alpha, pengujian beta yang melibatkan penggunaan akhir akan dilakukan (mahasiswa).

\section{f. Distribution (Pendistribusian)}

Tahap ini juga dapat disebut tahap evaluasi untuk pengembangan produkyang sudahjadisupayamenjadilebih baik. Hasil evaluasi ini dapat digunakan sebagaimasukan untuk tahap concept pada produkselanjutnya.

\section{PEMBAHASAN}

Penggunaan digital teknologi dalam pembelajaran dapat digunakan untuk meningkatkan partisipasi belajar siswa (Paulson, 2011). Model multimedia berbasis android yang dikembangkan dalam pembelajaran tari ini dapat mendukung hasil penelitian tersebut, karena memiliki sifat digitalisasi yang dapat diakses mahasiswa dalam berbagai perangkat media belajar seperti, laptop, komputer, smart phone, dan teknologi sejenisnya. Digitalisasi menjadi karakter pembeda sumber-sumber tersebut. Inovasi teknologi digital dalam pembelajaran praktek tari mampu mewujudkan gaya dan budaya mengajar saat ini dalam trend mode mengajar secara online (Anderson, 2012). Multimedia pembelajaran tari rakyat berbasis android ini relevan dengan berbesernya budaya mengajar konvensional menjadi modern dengan memanfaatkan media teknologi digital dalam implementasi pembelajarannya. Digital merujuk pada gabungan elemen perangkat keras (pemrosesan, memori, input dan komunikasi) dan perangkat lunak (sistem operasi dan program aplikasi) untuk melakukan berbagai tugas. Dengan demikian sumber belajar digital dipahami sebagai gabungan elemen perangkat keras dan lunak yang mempunyai potensi untuk mengatasi masalah belajar dan memfasilitasi kegiatan belajar (Ananiadou \& Claro, 2009). Di tegaskan pula oleh (Resnick, 2002) yang menyatakan bahwa transmisi dan mengakses informasi, sumber-sumber digital seperti komputer dapat dipandang sebagai material konstruksi yang menyediakan kesempatan yang luas dimana orang dapat berkreasi dan berekspresi. Kemampuan visualisasi, simulasi, games, dan interaktivitas, penggunaan sumber belajar digital telah membawa dampak bagi peningkatan kualitas pembelajaran terkait dengan motivasi, retensi, gaya belajar dan kreativitas (Underwood et al., 2007).

Teknologi dan media dua komponen pembelajaran yang turut menjadi kunci dalam mencapai kompetensi hasil pembelajaran (Palacios-Hidalgo, Gómez-Parra, \& Huertas-Abril, 2020). Pengembangan multimedia pembelajaran tari rakyat berbasis android ini mendukung ketercapaian kompetensi hasil belajaran mahasiswa dalam menguasai materi perkuliahan praktek tari di perguruan tinggi. Program riset ini seperti yang dilakukan (Risner \& Anderson, 2008) yang menjadikan pengembangan literasi teknologi digital dalam meningkatkan kualitas pengembangan kurikulum tari dalam lembaga. Motivasi ini melihat kecederungan mahasiswa saat ini memiliki ketertarikan tinggi terhadap teknologi khususnya media digital atau multimedia berbasis android yang digunakan dalam berbagai kegiatan pembelajaran, termasuk dalam perkuliahan tarirakyat. Multimedia pembelajaran tarirakyat berbasis aplikasi android ini cocok untuk memperkenalkan kepada mahasiswa sebagai pengembangan kemandirian mahasiswa dalam mempelajari materi perkuliahan tari rakyat yang tidak selalu harus berhadapan langsung dengan dosen mata kuliahnya.

Teknologi digital dalam pembelajaran tari dapat membatu siswa dalam mengajarkan teknik gerak dalam menari (Huddy, 2017). Media pembelajaran ini menyajikan segmen video yang mengajarkan secara jelas mengenai belajar teknik gerak tari rakyat mulai dari gerakan kepala, kaki, badan dan tangan. Dengan menggunakan media teknologi seluler dalam pembelajaran tari dapat membantu mengefektifkan waktu siswa dalam meningkatkan keterampilan menari(Lin, Hsia, Sung, \& Hwang, 2019). Konsep ini yang dikembangkan dalam media pembelajaran tari rakyat berbasis android, dimana proses (Nagarajan, Velmanirajan, \& Kanna, 2013) pembelajaran tari rakyat dapat dilakukan oleh mahasiswa diluar jam perkuliahan, di luar kelas dengan menggunakan perangkat handphone yang mayoritas mahasiswa telah memilikinya sebagai perangkat alat pembelajaran masing-masing.

(Gratsiouni, Koutsouba, Venetsanou, \& Tyrovola, 2017) dalam penelitiannya memanfaatkan literasi teknologi seperti perkembangan youtube sebagai sumber belajar siswa. Dalam peneltian ini literasi teknologi yang dikembangkan dalam bentuk aplikasi android yang dapat diakses oleh perangkat mobile handphone masing-masing mahasiswa. Keuntungan lain dari media pembelajaran ini yaitu dapat menghemat biaya dan waktu latihan dapat ditentukan sesuai kemauan sendiri. Selain itu, pada media 
menyediakan materi pembelajaran tari rakyat secara lengkap sesuai dengan kebutuhan tujuan perkuliahan. Dalam terdapat pngetahuan umum tentang histroris perkembangan tari rakyat di Jawa Barat, penjelasan gerakan-gerakan dasar tari rakyat yang disajikan secara detail, materi quiz dan tayangan video materi taria lengkap yang harus dikuasai oleh mahasiswa selama perkuliahan satu semester. Oleh karena, konsep pengembangannya, sangat memperhatikan silabus perkuliahan yang dirancang dosen untuk setiap pertemuannya selama satu semester penuh.

\section{SIMPULAN}

Berdasarkan temuan penelitian ini, pengajaran perkuliahan tari rakyat menggunakan teknologi digital berbasis android dapat dipahami dan didekati secara kritis sesuai dengan kebutuhan aspek-aspek pendagogis dalam mengajar. Model teknologi media pembelajaran tari rakyat yang dikembangkan ini akan mampu mengubah gaya belajar konvensional menjadi modern dengan memanfaatka literasi teknologi sebagai sumber bejalar mahasiswa dalam menguasai materi perkuliahan yang diberikan oleh dosen. Desain media yang dikembangkan membantu mahasiswa dalam melakukan pembelajaran mandiri khususnya pada mata kuliah tari Rakyat yang diberikan di Departemen Pendidikan Tari FPSD-UPI Bandung, Beberapa kesimpulan lain dari hasil pengembangan model media pembelajaran berbasis android ini anataralain: 1) Materi media pembelajaran tari rakyat berbasis android ini didesain sesuai dengan kebutuhan perkuliahan tari Rakyat yang terintegrasi dengan silabus perkuliahan yang diberikan selama satu semester, 2) Konsep media pembelajaran berbasis android ini dikembangkan melalui pendekatan konsep pembelajaran self directed learning yang di desain sesuai dengan karakteristik pembelajaran mahasiswa sebagai individu yang mandiri, 3) Model media pembelajaran tari rakyat berbasis android ini mampu mewujudkan cara belajar generasi abad 21 (Mabingo, 2015) yang memanfaatkan literasi teknologi sebagai sumber belajar dalam era perkembangan indrustri 4.0.

\section{UCAPAN TERIMA KASIH}

Seiring dengan tersusunnya artikel ini, penulis ingin mengucapkan banyak terima kasih kepada semua pihak yang telah membantu proses penyusunan tulisan ini mulai dari melakukan kegiatan penelitian di Departemen Pendidikan Tari FPSD-UPI Bandung sampai pada penyusunan laporan kegiatan penelitian dan penyusunan artikel ilmiah yang diproyeksikan untuk dipublikasikan di Jurnal ini. Ucapan terima kasih ini juga Kami sampaikan kepada LPPM UPI yang telah meloloskan dan memberikan bantuan dana penelitian ini.

\section{DAFTAR RUJUKAN}

Almara'beh, H., Amer, E. F., \& Sulieman, A. (2015). The effectiveness of multimedia learning tools in education. International Journal of Advanced Research in Computer Science and Software Engineering.

Ananiadou, K., \& Claro, M. (2009). 21st century skills and competences for new millennium learners in OECD countries.

Anderson, J. D. (2012). Dance, technology, and the web culture of students. Journal of Dance Education, 12(1), 21-24.

Beishuizen, J., \& Steffens, K. (2011). A conceptual framework for research on self-regulated learning. In Self-regulated learning in technology enhanced learning environments (pp. 1-19). Brill Sense.

Bond, M., Marín, V. I., Dolch, C., Bedenlier, S., \& Zawacki-Richter, O. (2018). Digital transformation in German higher education: student and teacher perceptions and usage of digital media. International Journal of Educational Technology in Higher Education, 15(1), 1-20.

Brata, I. B., \& Sudirga, I. K. (2019). Megeguritan: Media Pendidikan Karakter Generasi Muda Dalam Menghadapi Arus Budaya Global (Studi Kasus Di Desa Pakraman Bresela Payangan Gianyar). Mudra Jurnal Seni Budaya, 34(2), 230-238.

Budiman, A., \& Amadi, D. N. (2016). Development of Dhungkrek Dance Learning Application to Preserve Local Culture Existence. International Journal of Advanced Research in Computer Science, 7(3).

Castañeda, L., \& Selwyn, N. (2018). More than tools? Making sense of the ongoing digitizations of higher education. Springer.

DeWitt, D., Alias, N., Siraj, S., Yaakub, M. Y., Ayob, J., \& Ishak, R. (2013). The Potential of Youtube for Teaching and Learning in the Performing Arts. Procedia - Social and Behavioral Sciences, 103, 1118-1126. https://doi. org/10.1016/j.sbspro.2013.10.439

Dick, W., Carey, L., \& Carey, J. O. (2005). The systematic design of instruction.

Falahudin, I. (2014). Pemanfaatan Media dalam Pembelajaran. Lingkar Widyawiswara, 1(Desember), 104-117. 
Fletcher, J., Everatt, J., Mackey, J., \& Fickel, L. H. (2020). Digital Technologies and Innovative Learning Environments in Schooling: A New Zealand Experience. New Zealand Journal of Educational Studies, 1-22.

Gibbons, M. (2003). The self-directed learning handbook: Challenging adolescent students to excel. John Wiley \& Sons.

Gratsiouni, D., Koutsouba, M., Venetsanou, F., \& Tyrovola, V. (2017). Learning and Digital Environment of Dance - The Case of Greek Traditional Dance in Youtube. European Journal of Open, Distance and E-Learning, 19(2), 80-95. https://doi.org/10.1515/eurodl-2016-0009

Huddy, A. (2017). Digital technology in the tertiary dance technique studio: expanding student engagement through collaborative and co-creative experiences. Research in Dance Education, 18(2), 174-189. https://doi.org/10.108 0/14647893.2017.1330327

Indonesia, P. R. (2003). Undang-undang Republik Indonesia nomor 20 tahun 2003 tentang sistem pendidikan nasional. Jakarta: Pemerintah Republik Indonesia.

Istiyani, D. (2009). Kesadaran dan self-directed learning sebagai model pembelajaran alternatif dalam era neoliberalisme. Edukasia Islamika, 7(2), 89818.

Jarvis, P. (2004). Adult education and lifelong learning: Theory and practice. Routledge.

Jarvis, P. (2007). Globalization, lifelong learning and the learning society: Sociological perspectives. Routledge.

Jauhari, J. (2009). Studi Terhadap Penggunaan Multimedia Interaktif Dalam. Prosiding Seminar Nasional Penelitian, Pendidikan Dan Penerapan MIPA, 425-432.

Knowles, M. S. (1975). Self-directed learning: A guide for learners and teachers.

Kozma, R. B. (1991). Learning with media. Review of Educational Research, 61(2), 179-211.

Kurniawati, I. D., \& Nita, S.-. (2018). Media Pembelajaran Berbasis Multimedia Interaktif Untuk Meningkatkan Pemahaman Konsep Mahasiswa. DOUBLECLICK: Journal of Computer and Information Technology, 1(2), 68. https://doi.org/10.25273/doubleclick.v1i2.1540

Lee, K., Tsai, P., Chai, C. S., \& Koh, J. H. L. (2014). Students' perceptions of self-directed learning and collaborative learning with and without technology. Journal of Computer Assisted Learning, 30(5), 425-437.
Lin, Y. N., Hsia, L. H., Sung, M. Y., \& Hwang, G. H. (2019). Effects of integrating mobile technology-assisted peer assessment into flipped learning on students' dance skills and self-efficacy. Interactive Learning Environments, 27(8), 995-1010. https://doi.org/10.1080/10494820.2018. 1461115

Mabingo, A. (2015). Integrating emerging technologies in teaching Ugandan traditional dances in K-12 schools in New York City. Curriculum Journal, 26(2), 313-334. https://doi.org/10.1080/09585176.2015.1035734

Mayer, R. E. (2002). Multimedia learning. In Psychology of learning and motivation (Vol. 41, pp. 85-139). Elsevier.

Merriam, S. B., \& Baumgartner, L. M. (2020). Learning in adulthood: A comprehensive guide. John Wiley \& Sons.

Merriam, S. B., \& Brockett, R. G. (2011). The profession and practice of adult education: An introduction. John Wiley \& Sons.

Nagarajan, R., Velmanirajan, K., \& Kanna, K. S. (2013). Integrating Digital Technologies in Teaching Learning Process. I-Manager's Journal of Educational Technology, 10(3), 1-5. https://doi.org/10.26634/jet.10.3.2499

Palacios-Hidalgo, F. J., Gómez-Parra, M. E., \& HuertasAbril, C. A. (2020). Digital and media competences: Key competences for EFL teachers. Teaching English with Technology, 20(1), 43-59. Retrieved from https://bit. ly/2GHgDML

Papilaya, J. O., \& Huliselan, N. (2016). Identifikasi gaya belajar mahasiswa. Jurnal Psikologi, 15(1), 56-63.

Paulson, S. (2011). The use of ethnography and narrative interviews in a study of "cultures of dance." Journal of Health Psychology, 16(1), 148-157. https://doi. org/10.1177/1359105310370500

Putri, W., Rahmawati, P., \& Wiharsih, R. (2019). Multimedia Feasibility of Kondan Dance Interactive Learning for Junior High School Students. International Conference on Art and Arts Education (ICAAE 2018). Atlantis Press.

Rahman, S. R. (2019). Identifikasi Gaya Belajar Mahasiswa Pendidikan Biologi Universitas Sulawesi Barat. Jambura Edu Biosfer Journal, 1(1), 1-5.

Resnick, M. (2002). Rethinking learning in the digital age. The global information technology report: Readiness for the networked world .... 
Risner, D., \& Anderson, J. (2008). Digital Dance Literacy: an integrated dance technology curriculum pilot project. Research in Dance Education, 9(2), 113-128.

Roblyer, M. D., \& Doering, A. H. (2006). Integrating educational technology into teaching (Vol. 2). Pearson/ Merrill Prentice Hall Upper Saddle River, NJ.

Ru'iya, S. (2019). Urgensi Self Directed Learning Mahasiswa Aktivis Di Era Revolusi Industri 4.0 (Studi Kasus Di Program Studi Pendidikan Agama Islam Universitas Ahmad Dahlan Yogyakarta). Journal AlManar, 8(1), 123-138.

Rusdewanti, P. P., \& Gafur, A. (2014). Pengembangan Media Pembelajaran Interaktif Seni Musik Untuk Siswa Smp. Jurnal Inovasi Teknologi Pendidikan, 1(2), 153-164. https://doi.org/10.21831/tp.v1i2.2526

Rusman, D. K., \& Riyana, C. (2011). Pembelajaran berbasis teknologi informasi dan komunikasi. Bandung: Rajawali Pers.

Sliwka, A. (2008). The contribution of alternative education. Innovating to Learn, Learning to Innovate, 93. Sma, D. I., \& Pati, N. (2012). Pengembangan Media Pembelajaran Inovatif Kooperatif Musik Ritmis Berbasis Multimedia Di Sma Negeri 3 Pati. Catharsis, 1(2).

Tongpaeng, Y., Sribunthankul, P., \& Sureephong, P. (2018). Evaluating real-time thai dance using Thai dance training tool. 2018 International Conference on Digital Arts, Media and Technology (ICDAMT), 185-189. IEEE.

Triman, A., \& Abdillah, A. (2017). Kecerdasan Budaya dan Gaya Belajar Mahasiswa yang Merantau di DKI Jakarta. Majalah Sainstekes, 4(2).

Underwood, J., Baguley, T., Banyard, P., Coyne, E., Farrington-Flint, L., \& Selwood, I. (2007). Impact 2007 : Personalising learning with technology.

Watermeyer, R., Crick, T., Knight, C., \& Goodall, J. (2020). COVID-19 and digital disruption in UK universities: Afflictions and affordances of emergency online migration. Higher Education, 1-19.

Widiastuti, N. M. D. (2018). Inovasi Aplikasi Media Pembelajaran Tari Bali Berbasis Android. Mudra Jurnal Seni Budaya, 33(2), 287-295. 